\title{
VIII. On increasing the light of a common argand lamp
}

\section{Holthouse Esq.}

To cite this article: C. Holthouse Esq. (1840) VIII. On increasing the light of a common argand lamp, Philosophical Magazine Series 3, 17:107, 40-44, DOI: 10.1080/14786444008650105

To link to this article: http://dx.doi.org/10.1080/14786444008650105

曲 Published online: 01 Jun 2009.

Submit your article to this journal $๘$

Џll Article views: 2

Q View related articles ¿ 
experiments being kept under slight pressure and at an equable temperature of near $70^{\circ} \mathrm{Fahr}$.

Mixtures of this kind conducted through the vinous fermentation in silver and china vessels always afforded a larger quantity of ashes after evaporation and calcination than those made in glass apparatus. But upon the proportionate increase by this process in any experiment, we can speak at the outset with as little certainty as upon the height to which any plant will grow when the seed is first planted. One of the features which I have always found to accompany their formation is an increase in colour, which colour again disap. pears when they undergo decomposition by the putrefactive fermentation and have ammonia as a product.

I have found the quantity to vary with almost every circumstance, even in experiments made with the same mixture, from little or no increase to that of twenty times the weight of those included in the sugar experimented upon. My experiments made with solutions containing about ten per cent. of their weight of sugar (the strength employed by Mr. Smith) rarely gave more than an appreciable increase upon the original quantity, except when the fermentation was conducted very quickly.

The ashes were obtained by evaporating and burning over a spirit-lamp without the addition of any foreign agent, the materials being in an open platinum vessel. Their quantity was determined by weight as a whole, with the addition of their power of neutralizing acids as regards their alkaline property.

Walworth Road, April 14th, 1840.

VIII. On Increasing the Light of a common Argand Lamp. By C. Houthouse, Esq.*

To the Editors of the Philosophical Magazine and Joumal. Gentremen,

HAVING seen in the Number of your Magazine of March last, a letter from Sir J. Herschel, "On a simplemode of ohtaining from a common Argand Oil Lamp a greatly increased quantity of Light," I take the liberty of sending you a few observations of my own on the same subject; they are mostly corroborative of what has been advanced by the distinguished philosopher before alluded to, and if you think them worth insertion they are very much at your service.

* Communicated by the Author. 
The size and brilliancy of the flame in a common Argand oil lamp depend chiefly upon the shape and dimensions of the glass chimney, and its position in relation to the flame; but as the contrivances which render the latter more brilliant at the same time diminish its bulk, there is a limit, beyond which we cannot increase the brightness without diminishing the illuminating power; the increase in brilliancy not conpensating for the diminished bulk of the flame. Sir J. Herschel has not told us what is the diameter of his Argand burner, or the diameter and form of his glass chimney; but from the description he has given us of his method of producing a greatly increased quantity of light, I presume he must have used one of those chimneys which are commonly employed only for gas lamps, being a simple cylinder about nine inches long, and of equal diameter throughout. But this kind of chimney is ill adapted for enlivening a flame, and seems merely to serve for protecting it against currents of air, although, when employed in the manner recommended by Sir J. Herschel, its office is reversed; it becomes a mean of increasing the intensity of combustion, but serves no longer as an efficient protector: and in this latter respect it is imperfect; for admitting the advantages which arise from the increase of light, still these can only be available while a lamp is at rest: the instant it is moved the flame must necessarily impinge against the walls of the chimney, at the great risk of breaking it, and with a certainty of smoking it. But an equal degree of light, and not subject to the inconvenience just mentioned, can be obtained by one of the chimneys ordinarily made use of in the common table lamp, which consists of a base or larger cylinder, upon which the pillar or smaller cylinder is joined lyy a horizuntal part, termed the shoulder: upon the height of the pillar of this chimney, the proportion of its constituent parts to each other and to the burner, and their position in relation to the latter, depend the efficient burning of the lamp.

And first with reference to the height. The most obvious effect of lengthening a chimney is, to render the flame more flickering and unsteady, at the same time its brightness is slightly increased, and its bulk diminished: the larger the diameter of the chimney compared with the burner, the less marked are these changes. On lengthening a chimney whose pillar had a diameter of $1 \frac{1}{8} \mathrm{inch}$, to three feet, and placing it on a lighted lamp, well turned on, whose wick had $\frac{7}{8}$ of an inch diameter, the flame immediately split into several small flickering cones, the largest of which was not above five or six lines in height; as the chimney was shortened, so did the 
flame in the same proportion become steadier and more uniform, till at seven inches, which was the length of the pillar of this chimney, it was as steady as could be desired. One fact was strikingly obvious during this experiment, viz., that the increase of brilliancy was by no means commensurate with the loss of light occasioned by the smaller bulk and great unsteadiness of the flame. From several trials with chimneys of various lengths, I should say that a seven inch pillar, for an Argand burner of the ordinary size, is well adapted for giving brightness, and at the same time steadiness, to a flame.

To ascertain the best diameter for the chimney, eight pieces of tin were procured, each two inches square, and having a circular aperture in their centre, varying from one and a half to half an inch in diameter; these, by turns, were fixed to the moveable stage of a microscope, and then placed directly over the flame of a lamp, so that the centre of the circle of the Argand burner should correspond with the centre of the circular aperture in the tin; a simple* glass chimney being now placed upon the tin, the whole apparatus was lowered till the flame of the lamp passed through the aperture in the tin. By trying the different sizes one after the other, we were able to decide upon that which gave the greatest degree of illumination, and by raising and lowering the apparatus over the flame, the best height from the level of the wick for obtaining the greatest light was determined. The following are some of the results. The size of the flame was in a direct ratio with the size of the aperture in the tin, but its brilliancy was in an inverse ratio; in other words, the flame diminished in size but increased in brilliancy as the aperture through which it had to pass was lessened. The effect produced by chimneys of different diameters, but of equal length, provided the aperture in the tin over which they were placed remained the same, was so trifling, that it was scarcely appreciable : the diameter of the aperture in the tin being, for instance, one inch, and that of the chimney the same, no material alteration in the brilliancy or bulk of the flame was produced when a chimney of double the diameter was substituted for it. I need hardly observe, that the diameter of the chimney must not be less than that of the tin. I said at the commencement of this letter, that there was a limit beyond which we could not increase the bright-

* When I apply the term simple to a chimney, I wish to be understood as speaking of those cylinders of uniform diameter from end to end; those composed of two parts, I shall, to prevent unnecessary tautology, designate compound. 
ness of the flame without diminishing its illuminating. power. I am not at present prepared to say where this precise point is; but I can assert, without fear of contradiction, that an aperture of one and one-eighth of an inch diameter, for a lamp whose wick is seven-eighths of an inch, is a size well calculated for giving a great degree of brilliancy to the flame, without materially diminishing its bulk. We come now to the consideration of the best height for placing the plate of tin above the wick of the lamp; this appears to be from twoeighths to three-eighths of an inch, which is that specified by Sir J. Herschel, supposing his burner to have an inch diameter: when we go below this the flame becomes brighter, less coniform, and shorter; the continuity of its circle is interrupted; chasms form in it, producing the appearance of so many distinct flames; and when the tin has reached the level of the wick, the lamp is well nigh extinguished. Sir J. Herschel, in describing the effect produced on the flame by raising and lowering the chimney, has suggested that it would be an improvement were our common lamps provided with a mechanism for this purpose; this has actually been done on the continent, and in this country by Mr. Samuel Parker of Piccadilly, the flame of whose hot-oil lamp is regulated entirely by raising and lowering the chimney, the wick remaining stationary. Now if a number of glass chimneys be made, the diameter of whose pillars shall be the same as those of the apertures in the tin, and these be suspended over the flame with their narrow end downwards, we shall have the same result: but if, instead of this, they be placed in the usual manner on their support, the large end lowermost, we shall still have precisely the same result, provided the commencement of the pillar bear the same position, in reference to the wick, as the upper end did when suspended over it. The diameter of one inch and an eighth, which I have named as a good size for having the pillar of the chimney, is eligible likewise on another account : there is less danger of its becoming smoked, to which it would be very liable were it of smaller dimensions than that just specified. The base of the chimney may be an inch and three-quarters or two inches in diameter, and its shoulder should form a right angle with the level of the burner, about half an inch above it. This is a form of chimney which I have proved to be well fitted for giving a degree of light very superior to what is seen in Argand lamps having the ordinary sized chimneys. Dr. Ure, in a very interesting paper read before the Institution of Civil Engineers in June last, seems to give the preference to chimneys with rounded shoulders; these certainly give greater steadiness to the flame, 
and if the light is equal to that afforded by the rectangular shouldered ones, they should be preferred.

One more point, which was barely touched upon by Sir J. Herschel, yet remains to be decided: Is this superior splendour of the flame attended by an increased consumption of oil? If we reasoned from analogy, we should certainly reply in the affirmative; intensity of combustion being ever attended with corresponding consumption of the combustible material. But to place this beyond a doubt, the following experiment was undertaken. Two Argand lamps, having wicks and chimneys of the same diameter and length, and furnished with the same kind of oil, were placed in a pair of scales, each at an equal distance and elevation from the centre of a sheet of white paper pasted on the wall. On being lighted, the flames were regulated till the shadows cast by a small ruler had an equal depth; when this had been fairly determined both by myself and others, weights were put into the stand containing the lighter lamp, till the two exactly balanced each other. The chimney was now quickly removed from one of the lamps, and another substituted for giving a clear white flame, the time being at the same moment noted: they were allowed to burn for forty-two minutes, and were then simultaneously extinguished. At the expiration of this time, the lamp burning with the bright flame had consumed 100 grains more than the other. The experiment being repeated, but with smaller flames, the increased consumption of oil in the bright burning lamp was 50 grains. Whether this greater expenditure of oil is balanced by the increased degree of illumination, and the solution of some other interesting questions connected with this subject, I shall reserve till a future period. I am, Gentlemen, Your obedient Servant,

13, Keppel Street, Russell Square,

C. Holthouse. April 11, 1840.

1X. A Letter to Prof. Faraday, on certain Theoretical Opinions. By R. HaRE, M.D., Professor of Chemistry in the University of Pennsylvania *.

DenR Sir,

1. THAVE been indebted to your kindness for several 1 pamphlets comprising your researches in electricity, which I have perused with the greatest degree of interest.

- From Silliman's American Journal of Science and Arts, Vol. 38, No. I.

[We have taken the liberty of numbering the paragraphs of Dr. Hare's letter.-ED.] 